apenas no concernente às normas pròpriamente mercantis, senão sob influir na sua aspectos, adiantou-se ao direito civil vigente, vindo a Em que posterior renovação.

Em que pese a crítica que se lhe irroga de já ter nascido velho to com os três precede para o meio, uma lei progressista. No confronbrasileiro revela-se aloum que the serviram de modêlo, o Código mente aos códigos espanhol tanto melhor. Talvez por isso, contràriaprazo, pouco mais de vários títulos e acrescido doutr anos, o nosso, embora já alterado em te, resistiu a acão do tempouros, mesmo assim, em grandíssima par-

políica do pais e na sua ses cem anos, $e$ assim também do apreciarificadas no decurso dêscomércio, o velho Código em do apreciável desenvolvimento de seu estado de coisas se tem prestado resistido galhardamente. $E$ ao novo torpeceu a contím tem prestado admiràvelmente, tanto que jamais en De onde the e crescente expansão dos negócios.

haja escapado ao vêzo reformista tanha vitalidade? Como explicar ânsia de inovação, que fêra a sta, tão caro à nossa versatilidade $e$ à 6 - E' realmente de espantar de governos ocasionais?

vivido tanto, máxime nos últimos tempo a vetusta lei mercantil haja pruridos reformistas, vem se quanto diz respeito ve votando soberano desprêzo por tudo

Avulta a estranheza, porque não faltaram vozes autorizadas $e$ Em condicões tais, da reforma.

do Código. Para um país novo um milagre essa sobrevivência longeva bia léntidão que, ao invés de inérciapirito trêfego, pouco afeito à sáoportunidade, o Centenário inércia, significa ponderação e senso de especial.

Neste breve artigo, basta assinalar o acontecimento, de si só altamente significativo: a 25 de junho dêste ano, o Brasil comemora o Centenário de seu Código do Comércio, promulgado pelo Lei n. 556,

Honra se faça aos notáveis estadistas do Império, aos quais devemos tão sábia Lei! Que a mocidade de hoje saiba lembrar e cultuar o nome dêsses nossos maiores, como preito de justiça e afirma ção do sentimento pátrio!

(2) Desta ordem é o reparo de HUGo SIMAS (Compêndio de Direito Marítimo apesar de jâ existente desde 17.88 .

\section{DO DIREITO MARÍTIMO (*)}

\section{André da Rocha}

- Sentido da expressão. 2 - Direito marítimo público ou administrativo. 3 - Direito marítimo internacional. 4 - Direito marítimo privado. 5 - Distinção entre o direito comercial terrestre e marítimo. 6-Unificação didá tica e legislativa do direito comercial. 7 - $O b$ jeto do direito comercial marítimo. 8-Do mar como objeto do direito comercial marítimo.

1 - A expressão "Direito Marítimo" tem úm significado amplo porque compreende as normas reguladoras de quaisquer relações que surjam do exercício da navegação ou que decorram do uso do navio. Compreende, portanto, no sentido lato, tôdas as normas que se referem exclusivamente à navegação marítima. E como sejam elas pertencentes, em parte, ao direito público, em parte ao internacional e, ainda, ao direito privado, daqui resulta que o direito marítimo pode ser considerado sob cada um dêstes três aspectos e ser, então, classificado em direito marítimo público, ou administrativo, direito marítimo internacional e direito marítimo privado, ou direito comercial marítimo.

2 - O direito marítimo público ou administrativo é aquêle que regula as relações da marinha mercante, ou melhor, da navegação marítima com o Estado, como pessoa jurídica de direito público. Entram na esfera dêste ramo assuntos variadíssimos, entre êles o da nacionalização do navio, a navegação de cabotagem, eis que não são todos os navios que podem fazê-la, as disposições concernentes à polícia marítima e de portos, à matrícula das embarcações, do pessoal que se entrega à vida do mar, aos meios para evitar abalroamentos de navios, às condições de recebimento a bordo de práticos de portos e barras, e, ainda às relativas à segurança das embarcações e sanitárias.

(x) N.R. - Notas de uma aula do saudoso Prof. Des. Manuel André da Rocha, um dos fundadores desta Faculdade, cujos destinos regeu :com exemplar de dicação e proficiência durante 30 anos. Nesta data, em que a Instituicãa nário do Código Comercial, pareceu justificada a publicą̧ão destas notas sôbre matéria ainda pelo Código disciplinada. 
3 - O direito marítimo internacional ocupa-se da liberdade do mar, da navegação de mares, lagos, canais e rios da liberdade do comércio entre os Estados, etc. 4 - $\mathrm{O}$ direito marítimo

compreende as normas reguladorivado ou direito comercial marítimo navio e as relações jurídicas quadoras das relações criadas pelo uso do ticulares. Nesta acepcão menos dêsses usos podem surgir entre pardireito que regula, quase exclusivame o direito marítimo é parte do meio dos navios. $5-A$

restre, não corresponde, perfeitamentida, em direito marítimo e terobedece a um critério rigorosamente a um necessidade lógica, não

A circunstância de existiremente científico.

ro marítimo, o câmbio marítim alguns institutos, tais como o segusam ao comércio marítimo, não, etc., que, particularmente, interesmo do direito do domínio náo justifica o desprendimento dêste raparte, um direito autônio comum para constituir uma categoria à empréstimo terrestre direito comercial. Temos o e o transporte marítimo, emprestimo marítimo, o transporte terrestre tretanto, esta distincão, o seguro terrestre e o seguro marítimo. Enobjeto de um o objeto do observa nas legislações, apesar de ser o códigos, em disposicões separad São tratados, porém, nos respectivos França, em Portugal, etc.

todos os outros que a dmirar que o nosso Código Comercial, como nha acompanhado servilmente na segunda metade do século XIX, teprimeiro a estabelecer positivo.

adotando uma classifica legislador era lícito fazer, conservando ou histórica, não é admiśícl ou distinção, de importância meramente cial. Não se pode cientificamente dizer sistematizado de direito comertimo seja autônomo. Não pode dizer que o direito comercial marírítimo privado se reduz ao estudo porque o conteúdo do direito made navios, equipagens) ao estudo das pessoas, (armadores, capitães de navios, equipagens) e dos contratos que se formam pelas relações zado, podem, Tais matérias, em estudo sistematitiva ao comércio terrestre, ser encaradas e examinadas na parte relarestre e do direito comerrestre porque o conteúdo do direito comercial terdos fatos e das relacónercial marítimo ficam compreendidos na ordem Esta é a opinião de Esta é a opinião de ENDEMANN, MARGHIERI, COSACK
outros.

6 - O notável professor de São Paulo, dr. Brasílio Machado, no programa de ensino apresentado à Faculdade de Direito daquela $\mathrm{Ca}$ pital, bem compreende quanto de prejudicial à unidade do ensino tem essa distinção; opina seja o ensino do direito comercial e marítimo mi-

nistrado sistemática e paralelamente. Em sua opinião, o estudo do direito comercial, assim em conjunto, corresponde a uma necessidade do ensino e satisfaz as exigências da lei.

Justificando seu programa, aliás aprovado pela Congregação daquela Faculdade, assim se exprime o professor paulista:

"O curso desta cadeira foi metòdicamente delineadc sôbre um programa novo, que bem corresponde às exigências da lei e satisfaz as necessidades do ensino.

Criando duas cadeiras de Direito Comercial no cursc de ciências jurídicas, a lei não pretendeu por isso mesmo dividir as matérias, aliás, vastíssimas que aquela disciplina inclui; fêz de uma cadeira a seqüência de outra, sem linhas demarcatórias, sem solução de continuidade no ensino, - distribuiu, como a muitos parece, para o terceirc ano o conjunto de preceitos que afetam mais diretamente ao comércio em geral e ao comércio terrestre, reservando para o quarto ano, seja qual fôr o intervalo deixado no curso anterior, o doutrinamento exclusivo do direito $\mathrm{co}-$ mercial marítimo e do instituto da falência. Seria fragmentar em demasia a unidade da ciência e destarte ministrar um ensino defeituoso e quebrado no seu nexo científico".

A cadeira não está de acôrdo com a opinião do abalizado mestre; pensa que um curso sistematizado do direito comercial deve ser feito realmente, atendendo-se à desejada unificação da matéria. Como modêlo de um programa para um curso sistemático, êsse, que o professor Machado apresentou e foi aprovado, é aceitável. Mas entende a cadeira que não se deve encarar o assunto de um ponto de vista abstrato; o programa devia obedecer ao regulamento da. Faculdade, segundo o qual o ensino do direito comercial marítimo, bem como falência, constitui objeto do quarto ano. Se a lei assim o quis, embora daí resultem inconvenientes, tal como o de quebrar a unidade do ensino, não há fugir ao cumprimento dessa disposição.

$O$ aplicador da lei não pode sobrepor o seu pensamento, à vontade, ao pensamento do legislador. $E$, evidentemente, não fôra outra cousa o que fêz o dr. BRASÍLIO MACHADO.

Assim, se o seu programa corresponde a uma necessidade do ensino, não é, todavia, aceitável em face da lei. Façamos, porém, votos para que estas disposições da lei MAXIMILIANO desapareçam, cometendo-se às Congregações das Faculdades organizar a distribuição das matérias de ensino, ou então, como disse o professor paulista, pela adotação de um programa que, respeitando as peculiaridades do comércio terrestre e marítimo, combine num só corpo o ensino de um e outro, evitando a sua fragmentação. 
Há a notar ainda, entre os nossos escritores, a opinião de CARLOS DE CARVALHO:

"Não é mais uma questão de substância a distinção entre o direito comercial e o civil. O que diz respeito ao comércio marítimo não pode impedir a reintegração e unificação do direito privado.

As embarcações entram na distinção dos bens; a aquisição e perda da sua nacionalidade não oferecem embaraços. A navegação encontra no mandato, na gestão de negócios, na locação de serviços, no contrato geral de transporte, no mútuo, no penhor, na responsabilidade civil e na satisfação do dano as relações a que dá lugar”.

(Nova consolidação das leis, pg. LX).

RODRIGO OTÁVIO, transcrevendo esta lição do mestre, expõs também sua opinião e assim conclui:

"Não há negar, porém, que històricamente existiu essa autonomia, ou ao menos, uma inteira independência de outros corpos de doutrina e de lei, e não se pode deixar de ver conveniência em que tôdas essas relações que entendem com o navio e a indústria da navegação sejam tratadas no seu conjunto num corpo sistemático, quer como direito positivo, quer como doutrina. (Rev. Jurídica, vol. 17, pg. 170).

E' justamente uma razăo de clareza, de método, que aconselha se ponha têrmo à chamada autonomia do direito marítimo.

De fato, o dono do navio pode ser estudado conjuntamente com a pessoa do comerciante. O capitão, os oficiais de bordo e o pessoal da equipagem podem ser, para êsse fim, equiparados aos gerente e prepostos do comerciante. $\mathrm{O}$ transporte marítimo pode ser compendiado com o transporte por via férrea. Do mesmo modo, se correspondem o contrato de mútuo e o empréstimo náutico, o seguro de mercadorias a bordo do navio e o seguro de mercadorias depositadas nos armazéns. O navio pode ser equiparado ao estabelecimento comercial e assim por diante.

7 - Constitui objeto do direito comercial marítimo os navios, as avarias, os contratos de seguro e de câmbio marítimo, o fretamento de navios, o transporte de passageiros, os fatos geradores de responsabilidade, decorrentes do exercício da navegação, etc. .

Esse conjunto, integrado por coisas, fatos e atos jurídicos, constitui a matéria que forma o conteúdo do direito comercial marítimo
Revista da Faculdade de Direito de Pôrto Alegre

privado. Foi o pretenso peculiarismo dessa matéria que, no curso da volução histórica, facilitou a bi-partição do direito comerçal, forçando a distinção até agora mantida.

8 - SILVA COSTA considera "o mar como o primeiro e mais vasto objeto do direito comercial marítimo".

Em sua preciosa obra, escreveu êste comercialista:

"O mar é antes o teatro do que objeto dêste ramo do iretanto, são tão extensas as relações jurídicas que emergem do uso do mar e águas navegáveis e tão proeque energem do uso rítmicos do comércio minente o seu papel nos movimentos rítmicos d que dêle tira o qualificativo, que em geral é considerado que de mais vasto objeto do direito comercial como o (Direito Comercial Marítimo, tomo I, n. 20).

Não parece aceitável a opinião dêste abalizado mestre. Por mais tensas que sejam as relacões jurídicas que emergem do uso do mar prominente que seja o seu papel no desdobramento das relapor mais proeminente que seja o seu papel no desdobramento das rela-
çôes comerciais, o mar não pode, por isto, ser considerado objeto do direito comercial marítimo e não pode, da mesma forma, ou pela mesmaza porque a terra, a parte sólida do planêta, não é objeto do direito comercial terrestre.

Não se pode afirmar que o transporte por terra, pelas ferrovias, astados, qué vão cortando continenque atravessam os terris ex a mais tes, estreitando as relaçoes dos povos, éç, não tenham importância assinaladas e completas diferenças etnicas, não ten

não prestem grandes serviços ao comércio em geral. direito comercial

Entretanto, a terra não constitui objeto do direito comercial terrestre, porque ela é, em face do direito, apenas um vasto teatro em nada mais. 